Edith Cowan University

Research Online

Research outputs 2014 to 2021

$5-4-2018$

Gauging the development of innovative capabilities in accounting and finance students: Can they drive the national innovation agenda?

\author{
Denise Jackson \\ Edith Cowan University
}

Follow this and additional works at: https://ro.ecu.edu.au/ecuworkspost2013

Part of the Business Commons, and the Education Commons

10.1111/acfi. 12371

This is the peer reviewed version of the following article: Jackson, D. (2020). Gauging the development of innovative capabilities in accounting and finance students: Can they drive the national innovation agenda? Accounting \& Finance, 60(3), 2689-2715., which has been published in final form at https://doi.org/10.1111/ acfi.12371. This article may be used for non-commercial purposes in accordance with Wiley Terms and Conditions for Use of Self-Archived Versions.

This Journal Article is posted at Research Online.

https://ro.ecu.edu.au/ecuworkspost2013/9004 
This is the peer reviewed version of the following article: Jackson, D. (2020). Gauging the development of innovative capabilities in accounting and finance students: Can they drive the national innovation agenda?. Accounting \& Finance, 60(3), 2689-2715, which has been published in final form at https://doi.org/10.1111/acfi.12371. This article may be used for noncommercial purposes in accordance with Wiley Terms and Conditions for Use of SelfArchived Versions. 


\section{Gauging the development of innovative capabilities in Accounting and Finance students: Can they drive the national innovation agenda?}

\section{Introduction}

Australia has relatively poor performance in innovation efficiency; that being the translation from innovative capabilities into innovation outputs (see Jackson et al., 2015). This is attributed, in part, to relatively weak managerial capabilities and poor innovation culture (Department of Industry, 2012). To sustain global competitiveness and economic growth, there is a critical need to develop our workforce to better drive the innovation agenda. Graduates are expected to operate as critical and reflective practitioners and be tomorrow's leaders (Trede et al., 2012). They must acquire the capabilities to drive innovation (Bjornali and Støren, 2012) and convert new ideas to new or improved products, processes or business models (Utterback, 2004).

There has been some research on the capabilities developed at university that can promote innovative behaviour in the workplace (see, for example, Cerinsek and Dolinsek, 2009; Hayton and Kelley, 2006). These include technical expertise; analytical thinking; problemsolving; the ability to lead and coordinate others; identification of new ideas; communication and negotiation skills (see Bjornali and Støren, 2012); and risk aversion and confidence in tackling unfamiliar problems (Ritzen, 2016). Recent reports exploring the impact of globalisation and automation also emphasise the importance of a collaborative mindset and entrepreneurial capabilities (Committee for Economic Development of Australia [CEDA], 2015; Evans et al., 2016), including technical, negotiation and networking skills (Bjornali and Støren, 2012). Foundation for Young Australians [FYA] (2016) highlights enterprise skills - including project management, organisational skills and digital literacy - which can be transferred across different job roles. 
It is widely believed that innovative capabilities can be nurtured in higher education through activities and programs that emphasise the practical application of technical knowledge and entrepreneurship (CEDA, 2015; Davies et al., 2011). The role of work-integrated learning, also known as experiential learning and cooperative education, is one pedagogical example that can enhance innovative capabilities among students (Davies et al., 2011; FYA, 2016). It involves students connecting with industry through authentic tasks and assessments such as internships, work-based projects, simulations and business incubators. It can be a valuable platform for fostering innovative capabilities through the application of discipline-based knowledge; development of certain non-technical skills; increasing confidence and selfesteem; exposure to organisational structures and cultures; and opportunity to connect with one's professional self (see Jackson, 2016a).

There has been limited attention to the capabilities required to drive innovation (Bjornali and Støren, 2012) and how they can be developed (Australian Council of Learned Academies [ACOLA], 2016). This study explores the development of innovative capabilities in higher education, from the perspective of students and new graduates. It identifies skill gaps and presents stakeholder strategies to better prepare graduates to operate innovatively in the workplace. The study is focused on the fields of Accounting and Finance and the research objectives are to: i) assess the extent to which Accounting and Finance students are developing innovative capabilities in higher education; ii) identify any variations in the development of innovative capabilities by denographic characteristics; and iii) identify stakeholder strategies to enhance innovative capabilities among Accounting and Finance graduates to improve Australia's innovation performance. 
The study uses existing national data and quantitative research techniques to achieve the targeted research objectives. Data were gathered from 57,031 students at both the commencing and completing stages of their degree program and 40,141 graduates from Australian universities six-months post-course completion. Following this introduction, the second section of the paper reviews literature on innovative capabilities and their development in new graduates. The third outlines the employed methodology and the fourth section presents the results of the study. In the fifth section, stakeholder strategies intended to enhance innovative capabilities among graduates entering the workforce are discussed. The final section concludes the paper with a review of limitations and directions for future research.

\section{Background review}

\subsection{Climate for innovation}

Australia is experiencing an ever-changing economy characterised by globalisation, rapid changes in technology, evolving consumer preferences and structural change (CEDA, 2015). Innovation encompasses the generation of new ideas and the testing and commercialisation of new products and processes (ACOLA, 2016) and is critical for Australia to succeed and remain globally competitive (CEDA, 2015). While innovation is high on the nation's agenda and permeates policy and practices in government, Australia has declining levels of venture capital compared with other OECD countries (Bell et al., 2014). Relatively weak research collaboration between higher education providers and industry and poor innovation outputs (Dutta et al., 2016) are often attributed to issues with commercialisation and intellectual property (Australian Industry Group [AIG], 2016). Strengthening the link between education and innovation policy through incentivising innovation - such as continuing and expanding the R\&D tax incentive (AIG, 2016) - and creating a culture of innovation are important (CEDA, 2015). 
While there are many determinants of innovation at an organisational, industry and sector level (see ACOLA, 2016), this study focuses on individual propensity to innovate. At this micro-level, developing an entrepreneurial mindset among new graduates and the confidence and skills for business start-up and creative practice will help drive innovation. Increasingly, individuals are creating their own employment (Hajkowicz et al., 2016) and this is likely to become more important for graduates given trends in oversupply and ongoing underemployment (Karmel and Carroll, 2016). Entrepeneurialism is critical to promoting innovation in the 'new economy' (AIG, 2016) and is bolstered by government initiatives such as the Entrepreneur's Program and CSIRO Innovation Fund. Higher education institutions provide fertile ground for incubator initiatives that nurture sound business start-ups through appropriate funding, guidance and mentoring (see Universities Australia, 2016). Australia is considered to be an environment where entrepreneurship can flourish (Acset et al., 2016).

\subsection{Innovative capabilities}

With digital disruption, it is not always possible to predict how future jobs will look and what skills may be required (CEDA, 2015). In preparation for the new economy, graduates need higher order skills that are transportable across different job clusters (FYA, 2016) and enable them to navigate and succeed in various working environments. There is broad on the types of skills and capabilities needed to innovate. Capabilities which facilitate enquiry and initiative (Lowden et al., 2011); critical thinking, civic responsibility, teamwork and judgement (McKinsey, 2014); adaptability and communication (AIG, 2016); proficiency in information technology, numeracy and literacy (Bell et al., 2014); and creativity, problemsolving and digital literacy (Hajkowicz et al., 2016; Howard, 2016). ACOLA (2016) asserts "innovation also requires people who understand business, systems, culture and the way society uses and adopts new ideas" (p. 17). Further, the new economy needs fluid knowledge 
(AIG, 2016), requiring graduates to be confident in applying their knowledge in a range of new and unknown circumstances and to change their skills as needed (Rosenberg, 2016).

Entrepreneurial skills, focusing on consumer needs and end-user deliverables, are important (Howard, 2016). Innovative individuals demonstrate intrapreneurship within the organisation - the translation of new ideas into tangible outcomes in the market - and Bjornali and Støren (2012) argue there are four clusters of competencies required to achieve this. First, technical expertise that requires analytical skills and the ability to generate ideas. Second, accountability for progressing ideas forward and the ability to work effectively with others. Third, communication and negotiation to ensure the availability of resources. Finally, the brokering aspect which involves acquiring and connecting knowledge across internal and external networks. Management and leadership skills - for the effective formation and coordination of small teams - are also important (Bell et al., 2014; Howard, 2016), along with skills in Accounting and Finance (Howard, 2016).

Accounting and Finance are no longer number crunching roles but encompass risk management, leadership and strategic decision making (see Jackling and De Lange, 2009) and therefore play an important role in driving innovation. In particular, Accounting is predicted to outsource some of its traditional responsibilities in future years - such as payroll, superannuation registration and invoicing (CEDA, 2015) - which is likely to augment a greater shift to managerial accountabilities, including continuous improvement. ACOLA (2016) notes the importance of diversity and skill mixes within teams and across the organisation for both individual characteristics and acquired skills - for feeding innovation. 
Many explore the required capabilities of new graduates and, more specifically, those who enter Accounting (Kavanagh and Drennan, 2008; Webb and Chaffer, 2016). There is overlap between attributes and skills highly desired in graduates, therefore making them more employable, and the capabilities important for innovation. While graduate employability is associated with improved organisational productivity and adaptability (see Guilbert et al., 2016), there lacks an explicit connection between employability and enhancing innovation. Innovative capabilities that extend beyond the non-technical skills traditionally associated with graduate employability (such as teamwork and communication) should be included in conceptual models of graduate employability and contemporary notions of work-readiness.

Previous research has indicated that certain demographic characteristics may influence an individual's propensity to innovate (see Bjornali and Støren, 2012). Bjornali and Støren reported males are more likely to be innovative and the likelihood of being innovative increases with age. Bantel and Jackson (1989) found an inverse relationship between average age and innovative performance yet this was not supported in Østergaard et al.'s (2011) study of employee diversity and innovation. Ardagna and Lusardi (2010) found males were more likely to be entrepreneurs and the average age of entrepreneurs was higher than nonentrepreneurs. Given these documented effects, this study explores their influence on the perceived development of innovative capabilities during degree studies.

\subsection{Interventions in higher education}

In line with human capital theory (Becker, 1964), innovation is determined by the capabilities of individuals, not least our graduates who are considered tomorrow's leaders and drivers of the future way of working. Here, higher education must develop the higher order skills required to drive innovation and provide an "education that ignites a student's passion for lifelong learning” (Australian Business

Deans Council [ABDC], 2016, p. 4). While there has been publicised flow through from the 
innovation agenda to higher education in terms of designing research which will positively influence our propensity to innovate, there has been far less attention to the impact of university curricula and preparing our graduates in the capabilities to innovate (Ritzen, 2016). Unfortunately, "the commitment needed to link education and innovation policy with funding is significantly lacking compared with other countries" (CEDA, 2015, p. 6) and despite increased pressure among higher education providers to deliver on higher order skills among new graduates, some evidence suggests continued dissatisfaction among employers (ACOLA, 2016; AIG, 2016). Many Accounting graduates are considered to lack certain skills and more focus is required on business process improvement, critical thinking and decision making (see Dale 2015). Rapid changes in the field of Accounting (Sin et al., 2012) can cause a misalignment between curriculum and developing the skills and knowledge required for contemporary professional practice. This is problematic given skill shortages are a significant barrier to innovation (ACOLA, 2016).

The National Science and Innovation Agenda (NISA) acknowledges the importance of higher education providers better engaging with industry yet, equally, employers must be keen to collaborate on developing students capabilities for the future. ABDC (2016) asserts "business and management skills are critical in delivering innovation, transferring technology and commercialising research" (p. 3) yet Business graduates are among those least likely to contribute to innovation in the workplace (Bjornali and Støren, 2012). This raises a red flag as Business education offers significant opportunity for acquiring entrepreneurial skills (Bjornali and Støren, 2012) through problem-based learning such as business incubators and entrepreneurial programs.

ACOLA (2016) emphasises the role of work-integrated learning in enhancing innovation as it "constitutes one way of building workforce capability with more holistic and higher-order integration skills and entrepreneurial expertise" (p. 102). It can be embedded across all 
disciplines at undergraduate through to $\mathrm{PhD}$ level and with a particular focus on exposing students to scenarios and environments that develop capabilities that foster innovation. It is also a useful platform for identifying the strongest talent pool that can then be channelled into graduate programs and roles targeting innovation (see ACOLA, 2016). It allows students to bring in fresh ideas from the classroom and facilitates the completion of shelved or delayed projects that may translate to innovative outputs.

Other initiatives for developing innovation during degree programs include innovation centres dedicated to identifying the entrepreneurial skills needed to successfully innovate and incubator centres which support new innovations. There is reported success in start-up businesses arising from student-led incubators and accelerator programs; along with the 'innovation ecosystems' which universities are establishing for establishing and growing businesses (Howard, 2016). Embedding innovative capabilities into core curriculum, "such as design thinking and digital literacy, collaboration and teamwork, and problem-solving" (ACOLA 2016, p. 100) is also important. Importantly, although this paper focuses on the acquisition of innovative competencies during degree programs, the external environment, structure and culture of an organisation will certainly influence individual capacity for innovation once a graduate enters the workforce (see, for example, ACOLA, 2016).

\section{Methodology}

\subsection{Participants}

A summary of characteristics of Accounting and Finance graduates sampled from the Australian national data sets, $N=10,727$ (2012), $N=10,537$ (2013), $N=10,143$ (2014) and $N=734$ (2015), is provided in Table 1. The characteristics of Business and Management students in the commencing ('comm') and completing ('comp') stages of their degree program are 
summarised in Table 2. There was very little variation in characteristics across the different survey years for both the new graduates (Table 1) and students (Table 2).

[Insert Tables 1 and 2]

\subsection{Procedures}

Two national secondary data sets were used to assess the extent to which innovative capabilities are developed in Accounting and Finance students. First, the Student Experience Survey (SES) that gathers data on different aspects of the student experience for the Department of Education and Training and informs institutional strategic planning. The survey is administered between August and October each year by the Social Research Centre to those commencing and studying in their final year of an undergraduate degree program in Australia. A unique online survey link is emailed to students with the utilisation of followup emails and SMS reminders. Awareness of the survey is developed prior to launch, including details of the incentive scheme to encourage responses. Institutions supplement promotion with internal emails, social media and on-campus posters. There were 100,225 completed surveys in 2013 with an overall response rate of 29.3\%; 99,112 completed surveys in 2014 with a response rate of $30.1 \%$; and 145,382 completed surveys with a $38.4 \%$ response rate in 2015. To enable comparison with earlier years, the completed surveys for universities in 2015 was 136,380 with a $37.9 \%$ response rate.

The Course Experience questionnaire (CEQ), managed by Graduate Careers Australia, measures perceived quality of undergraduate and postgraduate education among higher education providers. It is used to benchmark institutional performance in teaching and learning and is administered twice-yearly at an institutional level at graduation ceremonies or by email, mail, online or telephone. There were 137,699 completed surveys in 2012 with 
an overall response rate of 55.4\%; 138,661 completed surveys in 2013 and response rate of $54.6 \% ; 142,582$ completed surveys in 2014 with a response rate of 54.6\%; and 131,261 completed surveys with a 53.6\% response rate in 2015. Both the SES and CEQ are national surveys with sizeable samples and considered to provide valuable and reliable data. Ethical clearance was obtained for the study and no issues arose during the research procedures.

\subsection{Measurement of variables}

\subsubsection{CEQ and SES measures}

The CEQ comprises 49 attitudinal statements on the quality of completed degree courses. Participants indicate their level of agreement with the statements, using a five-point scale ranging from 'strongly disagree' to 'strongly agree'. The statements relate to 11 quality measures of their coursework degree with only the core areas of teaching quality, generic skill development and overall course satisfaction - comprising 13 items - being mandatory items for all institutions. This study draws on four items relating to generic skills and five items for graduate qualities, selected due to their alignment with innovative capabilities.

The SES comprises items that measure learning engagement, teaching quality, learning resources, student support and skills development, referred to as the Student Experience Questionnaire (SEQ). This study draws on four items on skill development where participants rate, using a five point Likert scale ranging from "not at all" to "very much", the extent to which their course developed skills relevant to innovative capabilities. In addition to demographic and contextual measures, the same four generic skills and five graduate qualities items from the CEQ are included in the instrument. Data for graduate qualities is only available for 2013 before the items were discontinued. 


\subsubsection{Selection of measures}

The four generic skills from the CEQ/SES comprised 'ability to work as a team member'; 'analytic skills'; 'problem-solving skills'; and 'confident about tackling unfamiliar problems'. The selected SEQ items were team-work, problem-solving and critical thinking skills. Teamworking was selected due to widespread acknowledgement of collaborative working underpinning innovation and economic advancement (Michaelis and Markham, 2017). Individuals with varied skill sets and knowledge operating in cross-functional roles will be part of future work (World Economic Forum [WEF], 2016) and are a key driver for managing current change and augmenting future improvement (World Bank Group, 2016). WEF (2016) states "business collaboration within industries to create larger pools of skilled talent will become indispensable, as will multi-sector skilling partnerships that leverage the very same collaborative models that underpin many of the technology-driven business changes underway today" (p. v). Collaborative arrangements may be face-to-face or virtual, calling on heightened abilities in communication and cooperation across different contexts.

Critical thinking and analytic skills are important for recognising gaps and forecasting trends so organisations can remain abreast of disruption (WEF, 2016) and create value and innovate (World Bank Group, 2016). The importance of graduates having both the ability and confidence for complex problem-solving is projected to increase amid disruptive changes on skill demands (WEF, 2016). In fact, Wojtczuk-Turek and Turek (2015) describe cognitive abilities - "problem recognition, generation of solutions and then their appropriate verification" - as "indispensable for effective appearance of innovation" (p. 400). The World Bank Group also underlines the importance of cognitive skills and team working as "things that are still hard for technology to replicate" (p. 125). 
The five graduate qualities were 'broad overview of my field of knowledge'; 'enthusiasm for learning'; 'confidence to investigate new ideas'; 'able to apply principles learned to new situations'; and 'value other perspectives'. The final SEQ item was also disciplinary knowledge that is considered fundamental to innovation (ACOLA, 2016) yet in combination with practical skills. Despite considerable attention in recent years on graduate mastery of non-technical skills, disciplinary knowledge is still considered important in graduate recruitment (Graduate Careers Australia, 2016).

Regarding the selection of 'enthusiasm for learning', curiosity generates an eagerness to learn and a desire to explore new ideas and is positively associated with innovation (Celik et al., 2016). Further, lifelong learning and ongoing pursuance of personal and professional development are agents of continuous improvement and innovation (Volles, 2016). In what WEF (2016) describes as the 'Fourth Industrial Revolution', it states 'it is critical that businesses take an active role in supporting their current workforces through re-training, that individuals take a proactive approach to their own lifelong learning and that governments create the enabling environment, rapidly and creatively, to assist these efforts" (p. v). Completion of a degree is one step in an individual's journey and seeking new opportunities for learning and development are interlinked with resilience, success and innovation (Barnes et al., 2016).

Confidence in suggesting improvements and undertaking challenges is necessary for innovative processes (Pons et al., 2016; Wojtczuk-Turek and Turek, 2015), making individuals more resilient in pursuing aims to an end result. Regarding ability to apply principles learned to new situations, the successful transfer of learning across different contexts is inherent to a contemporary economy characterised by rapid change and automation (FYA, 2016). Unfortunately, skill transfer is often overlooked in the design of education and graduate 
programs, assumed to simply occur automatically by stakeholders (Jackson and Hancock, 2010). Overtly acknowledging and gauging this capability in students and graduates is required to highlight inadequacies in this area and inform both future curriculum and graduate job design. Finally, valuing other perspectives was considered important in the context of digital disruption and the need to embrace change and working collaboratively with others to achieve improved outcomes. Wojtczuk-Turek and Turek (2015) review literature that highlights the need for openness to change and responding well to feedback. Openness to new ways of thinking is described by ACOLA (2016) as "indispensable for innovation" (p. 69).

\subsection{Analysis}

The CEQ dataset for Bachelor graduates was filtered for those completing degrees in Accounting, Finance and Banking. The SES datasets for 2013, 2014 and 2015 were combined and filtered to retain only those studying Business and Management (encompassing Accounting, Business Management, Sales and Marketing, Management and Commerce - Other, and Banking and Finance). This higher-level variable was selected to capture Business students who completed broad-level Business courses with majors in the areas of Accounting and Finance. A descriptive analysis of the skill development and graduate qualities measures in both data sets was undertaken, followed by an evaluation of variations in these items using MANOVA. Analysis was conducted using SPSS 23.0.

\section{Results and discussion}

\subsection{Innovative capabilities among students and graduates}

Student and graduate ratings of their courses' development of certain skills and capabilities are often used as a measure of educational quality (Nair and Shah, 2011). Oliver et al. (2014), in the piloted Employer Satisfaction Survey, found "graduates are a very reliable source of information about the quality of the qualifications they have recently completed and how well 
they meet labour market requirements" (p. 3). Table 3 presents the average ratings of new Accounting and Finance graduates on the development of the four generic skills and five qualities associated with innovation. The 'strongly agree' and 'agree' ratings were merged and the 'strongly disagree' and 'disagree' ratings merged to form an 'agree' and 'disagree' rating respectively. These, along with those who remained neutral, are presented in Table 3.

[Insert Table 3]

Results indicate a slight upward trend in the mean ratings for developing innovative capabilities across the four-year period. There were relatively high mean ratings in the combined sample, and across each year, for developing analytic skills, problem-solving skills and gaining a broad overview of field of knowledge. These increase the probability of contributing to innovation in the workplace (ACOLA, 2016; AIG, 216; Bjornali and Støren, 2012) and form an important component of the innovative skillset for new graduates. Broad skills in business and finance are critical for innovation (ACOLA, 2016) so the well-developed understanding of their field is a positive result. Findings broadly align with the piloted Employer Satisfaction Survey, (Oliver et al., 2014) which found favourabl ratings for disciplinary knowledge, critical thinking and analytical skills among both workplace supervisors and graduates. There were consistently favourable mean ratings for valuing other perspectives, ranging from 3.88 to 3.93, which aligns with Oliver and colleagues who found workplace supervisors considered graduates to have a strong capacity for understanding different viewpoints. Being able to apply principles learned to new situations also achieved reasonably strong mean ratings across the years, ranging from 3.85 to 3.89 . Mastery in transferring disciplinary expertise and skills across different contexts is critical with future work concentrated on project-based work in multi-functional teams and contract working. 
Although still above average, relatively weaker ratings were consistently recorded for ability to work as a team member; confidence in tackling unfamiliar problems; confidence to investigate new ideas and developing an enthusiasm for learning. This is problematic as confidence is critical for innovation (Ritzen, 2016) and enthusiasm for learning is a proxy for curiosity and enquiry, also important for innovation (Lowden et al., 2011). Enthusiasm for learning is a fundamental expectation of innovative employers with ACOLA (2016) noting "people have to be enthusiastic, willing to learn and broaden their skills along the way" (p. 73). Given the global emphasis on teams and collaborative working in the work landscape (Deloitte, 2016), team-working is certainly an area requiring improvement. Of note, the lower rating for teamwork is inconsistent with Oliver et al.'s (2014) finding where graduates rated teamworking as one of their stronger skills.

Table 4 summarises average ratings for innovative capabilities for the full sample of completing and commencing Business and Management students. Average ratings for the four items specific to the SES, in addition to the same four generic skills and five graduate qualities analysed for new graduates, are presented. The highest mean ratings for the CEQ items among completing students were for knowledge of field of study, problem-solving and analytic skills and aligned with the graduate results. As with the graduate sample, reasonably strong mean ratings were achieved for valuing other perspectives and applying principles learned to new situations. Also similar, relatively lower mean ratings were recorded for enthusiasm for learning; confidence in investigating new ideas; and confidence in tackling unfamiliar problems. Teamwork did not achieve a particularly strong mean rating and ranked sixth in magnitude, one above the graduate sample.

[Insert Table 4] 
Similar patterns in mean ratings were recorded for commencing students although ability to apply principles learned to new situations and valuing other perspectives ranked relatively higher. The same four items - team work, both confidence measures and enthusiasm for learning - achieved the lowest mean ratings. Significant differences in the mean ratings by commencing and completing students were recorded only for their ability to operate as a team member $(p=.002)$; analytic skills $(p=.041)$; confidence in tackling unfamiliar problems $(p=.000)$; and stimulating enthusiasm for learning $(p=.000)$. In fact, a relatively lower mean rating was recorded for developing an enthusiasm for learning among completing students. The small marginal differences, if any at all, in mean ratings assigned by commencing and completing students for the remaining items are disappointing and suggest higher education is adding little value in these particular aspects of the innovative skillset. These results raise concern as problem-solving; confidence to investigate new ideas; ability to apply principles to new situations; and valuing other perspectives are capabilities associated with graduates successfully transitioning from education to the workforce (Jackson, 2016b). One would expect higher ratings at the conclusion of the degree if higher education programs are to meet industry calls for work-ready graduates who can contribute upon entering the professional environment.

For the four SEQ items, the same pattern in mean ratings was recorded for both commencing and completing students. Knowledge of field of study achieved the highest mean rating, followed by critical thinking skills, teamwork skills and problem-solving skills. The development of disciplinary knowledge and analytical/critical thinking skills aligns with results from the graduate sample yet the relatively low problem-solving skills rating is disappointing, given the important role of higher education providers in developing this skills (Howard, 2016). Significant differences were recorded in mean ratings between commencing and completing 
students for all four skill areas $(p=.000)$ and certainly a more optimistic picture is created for the fundamental skill of effective team-working.

\subsection{Variations in innovative capabilities}

A series of MANOVAs was conducted for the combined graduate sample to detect variations in the development ratings of innovative capabilities. Significant MANOVA $(\alpha=.05)$ variations were reported for age, $\Lambda=.979, \mathrm{~F}(27,72619.264)=20.070, p=.000$, partial $\eta^{2}=.007$; gender, $\Lambda=.989, \mathrm{~F}(9,24858)=30.733, p=.000$, partial $\eta^{2}=.011$; residency, $\Lambda=.965, \mathrm{~F}(9,24867)=99.765$, $p=.000$, partial $\eta^{2}=.035$; and group-of-eight (Go8) status, $\Lambda=.986, \mathrm{~F}(9,24867)=38.836, p=.000$, partial $\eta^{2}=.014$. Significant univariate ANOVAs, with a Bonferroni correction $(\alpha=.013)$, are reported in Table 5.

[Insert Table 5]

Tukey post-hoc analysis $(\alpha=.05)$ indicated a consistent trend of older graduates assigning higher ratings to the development of innovative capabilities, other than for teamwork which reported a reverse trend. This is perhaps counter-intuitive as one might expect younger graduates, with less life and work experience, to have gleaned greater benefit from the teaching and learning of the innovative skillset. Females reported a relatively higher mean rating for the development of teamwork, enthusiasm for learning and valuing other perspectives with males awarding a higher mean rating for analytic skills and confidence in unfamiliar situations. Males are reported to be more self-confident than females (see Pons et al., 2016) and may achieve a heightened response in this area during teaching and learning processes, causing them to assign more favourable ratings than their female counterparts. Pons and colleagues assert the importance of social aspects of innovative behaviour for females, perhaps leading to their 
greater acknowledgement of and assignment of more favourable ratings to team-working and considering the viewpoint of others.

International graduates reported relatively higher mean ratings for the development of teamwork; confidence to investigate new ideas; enthusiasm for learning; and valuing other perspectives. They may have gained more benefit in these areas given the contrast to learning in their home country which may be underpinned by rote learning and deference to authority. In contrast, domestic graduates reported significantly higher mean ratings for developing analytic skills; broad overview of field of knowledge; and applying learning to new situations. There were mixed results for those graduating from Go8 universities with lower mean ratings in teamwork; confidence in investigating new ideas; and enthusiasm for learning. They did, however, record a higher mean for analytic skills; problem-solving; knowledge of field of study; and valuing other perspectives.

For Business and Management students close to completing their studies $(N=25875)$, significant MANOVA interactions were reported for age, $\Lambda=.945, F(42,7052.087)=3.233$, $p=.000$, partial $\eta^{2}=.019 ;$ gender, $\Lambda=.987, \mathrm{~F}(14,2379)=2.277, p=.004$, partial $\eta^{2}=.013$; residency, $\Lambda=.971, \mathrm{~F}(14,2379)=5.037, p=.000$, partial $\eta^{2}=.029$; and Go8 status, $\Lambda=.985, \mathrm{~F}(14$, $2379)=2.526, p=.001$, partial $\eta^{2}=.015$. Significant univariate ANOVAs, with a Bonferroni correction $(\alpha=.004)$, are reported in Table 6 .

[Insert Table 6]

Post-hoc analysis indicated those aged below 24 years assigned significantly higher ratings than those aged above 40 on developing the ability to work as a team member. Lack of exposure to team working in other aspects of their lives may have caused interventions to have a greater 
incremental impact on younger students. Conversely, the youngest age group assigned significantly lower ratings than older students on developing their confidence to tackle unfamiliar problems. Again, having greater self-confidence gained from life and work experience may have prompted mature students to perceive teaching and learning more favourably in this area. In 2013, there was a consistent trend for the youngest students assigning significantly lower development ratings than older students. This applied to gaining an overview of their field; developing an enthusiasm for learning; and being able to apply principles learned to new situations. Females recorded significantly higher mean ratings for developing students to value other perspectives and skills in complex problem-solving.

Domestic students assigned a significantly higher mean rating to their studies encouraging them to value other perspectives and developing knowledge of their field. Interestingly, the mean ratings were lower for all variables in the univariate analysis for those studying in Go8 universities (see Table 6). Comparing these results with those of the graduate sample, it seems that those studying at Go8 universities are less overtly aware of their capabilities development until they have graduated and are operating in the workforce.

\section{Implications for stakeholders}

The development of innovative capabilities in new graduates is a shared responsibility among educators, government and industry. As noted by ACOLA (2016), the skill requirements for innovation "set expectations not only for the design of undergraduate and postgraduate curricula, but also where companies need to invest in training and development, and what government needs to consider in designing frameworks for national strategies around skills development" (p. 97).

\subsection{Educators}


The study identifies key focus areas for initiatives intending to develop the capabilities required to drive the nation's innovation agenda. Attention to developing an enthusiasm for learning; confidence in tackling unfamiliar problems; confidence to investigate new ideas; and teamwork is required if graduates are to successfully innovate in the workplace. work-integrated learning has been identified as a useful platform for enhancing individual confidence through practice, reflection and feedback (Billet, 2011). It can also provide valuable insight into team-working processes in a student's chosen field (Freudenberg et al., 2011) and enhance collaborativeworking skills in students (Smith et al., 2014). Smith and colleagues also found that situated learning in the professional context augmented a greater appreciation for the value of learning in students and one would expect the exposure to fresh knowledge and real-life practice would foster greater enthusiasm for learning.

Work-integrated learning may also assist in developing areas that recorded weak marginal differences between commencing and completing students. It is important for developing disciplinary expertise through the integration of theory and practice (Smith et al., 2014). One would also expect improved student ability in applying acquired knowledge and skills in new situations through practice, with associated reflection and feedback, in unfamiliar contexts. In addition, the work-integrated learning experience introduces students to a professional network that may help them learn the value of other perspectives in regard to task and project completion, as well as for their own personal and professional development.

Given the resource intensive nature of work-integrated learning, it is important to embrace emergent, less traditional forms. A simulated 'Moot Court', for example, provides an excellent environment for Law students to practice their negotiation skills under the guidance and mentorship of both academics and legal practitioners. ACOLA (2016) highlight the importance 
of diversification and skill mixes in working teams so multi-disciplinary work-integrated learning programs enabling different students to work together on industry projects offer an excellent form of authentic learning. Indeed, Bjornali and Støren (2012) found that graduates who participated in project- and/or problem-based learning geared towards developing entrepreneurial skills while at university were more likely to contribute to innovation in the workplace. These innovative initiatives, and those utilising cutting-edge technologies, may also augment a greater enthusiasm for learning among students. Finally, greater concentration on developing skills in design thinking may improve student capabilities in solving complex problems (Howard, 2016).

There is, however, a lack of students participating in work-integrated learning (Edwards et al., 2015) and greater awareness among industry, professional associations and peak bodies of its importance is needed. The National Strategy (Universities Australia et al., 2015) is one step in highlighting the need for increased government resourcing and industry engagement with work-integrated learning to better develop workforce capacity and, more specifically, innovative capabilities. Other, less resource-intensive approaches to developing aspects of the innovative skillset include team-building courses, introductions on group-based learning processes and utilising peer evaluations in core curricula for developing team-working skills (Loughry et al., 2014). Industry engagement in the higher education setting - through guest lectures, mentoring programs and networking events - may enhance student confidence, their enthusiasm for learning, disciplinary expertise and the value they place on other perspectives. Campus-based capstone programs that draw on industry or community mentors, adopt crowdsourcing models and/or simulated models for unstructured problem solving can produce similar outcomes to work-integrated learning yet may be more easily upscaled for larger student cohorts. 
In relation to developing disciplinary expertise in line with the demands of the contemporary workplace, educators and industry must find communication channels that inform curriculum renewal and pedagogical interventions. Participation in consultative committees, or similar, is one way for industry partners to engage in the development of innovative-ready graduates. The enormity of ensuring workplace relevance cannot be underestimated and there is no place for ambivalence with WEF (2016) declaring "current technological trends are bringing about an unprecedented rate of change in the core curriculum content of many academic fields, with nearly $50 \%$ of subject knowledge acquired during the first year of a four-year technical degree outdated by the time students graduate (p. 20).

Initiatives for developing innovative capabilities should account for variations in student characteristics. It appears that younger students require additional support in developing innovative capabilities, although not in team working where targeted strategies should be introduced for mature students. A good starting point would be interventions to foster selfconfidence among younger students who may then respond more favourably to developing other aspects of the innovative skillset. The reported differences by residency status may be managed by developing a better understanding of the skill gaps arising from differences in curriculum, pedagogy and cultural outlook in the students' home country. Greater appreciation among educators of the idiosyncrasies experienced by males and females when developing innovative capabilities may produce better outcomes for all students.

Given their students assigned significantly lower mean ratings across all innovative capabilities, Go8 institutions should be adopting a holistic approach to reviewing their efforts, resources and practices in this area. As graduate ratings were far more favourable, educators 
may wish to introduce ways of more explicitly highlighting the development of capabilities to their student body. The introduction of an innovative capabilities framework would facilitate a rigorous curriculum mapping process and the overt embedding of skills into core elements of undergraduate programs. It is unacceptable to rely on extra-curricular or external activities such as volunteering and paid employment - to address gaps in development; a greater focus in the curriculum on areas of skill deficiency is required (ACOLA, 2016).

\subsection{Government}

The government needs to be proactive in acknowledging that more is required for developing innovative capabilities among new graduates. This may be achieved through greater support and resourcing of industry-education collaboration and the successful implementation of the national strategy (ABDC, 2016). Encouraging industry engagement with work-integrated learning may include tax incentives (ACOLA, 2016) and provision of support to SMEs (Universities et al., 2015) who are often ill-equipped to participate (Jackson et al., 2016). Academic engagement with industry through prioritising and rewarding engagement activities and encouraging secondments to industry (University of Melbourne, 2016) may also be useful in enhancing understanding of contemporary working practices and better integrating the development of innovation capabilities into future curriculum. In addition to existing programs designed to augment innovation, the University of Melbourne believe there is the need for additional interventions such as venture catalyst teams and the establishment of colocated collaborative precincts and hubs. The government also needs to invest in a new platform, to replace the Office of Learning and Teaching, which promotes and shares good practice to support quality student outcomes (ABDC, 2016). AIG (2016) argues greater acknowledgement of the role of the Vocational Education Sector in strategies for enhancing innovative capabilities in young adults would be helpful. Acknowledging the importance of 
lifelong learning is also critical and resource allocation for re- and up-skilling employees to enable the workforce to capitalise on disruptive changes is important (WEF, 2016).

\subsection{Industry}

While Bornjali and Støren (2012) found innovative capabilities feature in graduate recruitment and selection processes, more overtly emphasising these may encourage educators to place more importance on developing certain innovative capabilities (ACOLA, 2016). Organisations may augment innovative performance through increased focus on valueadd activities; implementing HRM processes to achieve the appropriate skill and diversity mix among staff; sufficient investment in skills and training; and high levels of networking with relevant stakeholders, including collaboration with higher education providers (ACOLA, 2016). ACOLA found the latter to be critical as strong collaboration with universities is apparent among innovative firms. This is achieved and demonstrated through strategic research partnerships, consultative committees, mentoring, and joint $\mathrm{PhD}$ projects; in addition to work-integrated learning where industry can directly assist in the development of students' innovative capabilities. Employers need to raise weak engagement levels with the latter (Department of Industry, 2014; Jackson et al., 2016b), often due to a lack of capacity for mentoring and supervising (Jackson et al., 2016).

Barriers to managing change and innovation include poor alignment between an organisation's workforce strategy and their innovation strategy (WEF 2016). In addition to re- and up-skilling employees in the noted skill areas, WEF advocates closer collaboration with the educator sector and greater exposure of employees to different roles. Mobility interventions, job rotation and placing graduates in multi-functional teams to develop skills for innovation more quickly and effectively could all prove useful. Findings also suggest that 
skills in innovation should not be assumed in new graduate recruits simply because they have completed a degree and investment is required by organisations to achieve innovation (Michaelis and Markham, 2017).

\section{Conclusion}

Graduates can play a critical role in the national drive for innovation. The study examined the extent to which new graduates and students, are prepared for and capable of contributing to innovation and growth in the workplace. It develops our understanding of how Accounting and Finance graduates and students perceive their development of innovative capabilities at the start and conclusion of their studies and post-graduation. It identifies areas for improving the development of innovative capabilities in higher education and presents stakeholder strategies to achieve this.

Accounting and Finance graduates and students believed those innovative capabilities that are best developed are analytic skills, problem-solving skills and gaining a broad overview of their field of knowledge. Areas for improvement were developing one's ability to work as a team member; confidence in tackling unfamiliar problems; confidence to investigate new ideas and developing an enthusiasm for learning. There were reported variations in ratings by gender, age, residency and whether studies were undertaken at a Go8 university. These emphasise nuances among student groups and target areas to enhance innovative capabilities among the graduating workforce.

As with all studies, there are limitations. The study uses self-report data that may be subject to rater bias (Van de Mortel, 2008) and produce overestimation of innovative capabilities, although this may not always be the case (Conway and Lance, 2010). Further, student and new graduate ratings of their satisfaction with skill development area used as proxies for 
actual development that is common although not necessarily accurate (Nair and Shah, 2011). Further, the analysis is constrained by the parameters of the SES and CEQ instruments and there are other capabilities that augment innovation that cannot be explored in this study. Future research could include examining the importance of self-awareness, proactivity and the ability to prioritise work (UK Commission for Employment and Skills, 2014); emotional intelligence (ACOLA, 2016); and networking skills (Ritter and Gemünden, 2003) for innovation and their development in higher education. Extending the study to explore different disciplines would add insight and allow for generalisations across the graduate cohort. 


\section{References}

Acs, Z., S. László, and E. Autio, 2016, The global entrepreneurship and development index (Springer International Publishing, Washington, DC).

Ardagna, S., and A. Lusardi, 2010, Explaining international differences in entrepreneurship: the role of individual characteristics and regulatory constraints, in Lerner, J. and Schoar, A., eds., International Differences in Entrepreneurship (University of Chicago Press, Chicago), $17-62$.

Australian Business Deans Council, 2016, Response to the Inquiry into Innovation and Creativity: Workforce for the New Economy (ABDC, Deakin, ACT).

Australian Council of Learned Academies, 2016, Skills and capabilities for Australian enterprise innovation (ACOLA, Melbourne, VIC).

Australian Industry Group, 2016, Response to the Inquiry into Innovation and Creativity (AIG, Sydney, NSW).

Bantel, K., and S. Jackson, 1989, Top management and innovations in banking: Does the composition of the top team make a difference? Strategic Management Journal, 10, 107-124. Barnes, S., A. Brown, and C. Warhurst, 2017, Education as the underpinning system: understanding the propensity for learning across the lifetime, (Government Office for Science, London, UK).

Becker, G, 1964, Human Capital: A Theoretical and Empirical Analysis, with Special Reference to Education (University of Chicago Press, Chigago, IL).

Bell, J., B. Frater, L. Butterfield, S. Cunningham, M. Dodgson, K. Fox, T. Spurling, and E. Webster, 2014, The role of science, research and technology in lifting Australian productivity (ACOLA, Melbourne, VIC).

Billet, S, 2011, Curriculum and pedagogical bases for effectively integrating practice-based experiences - final report (ALTC, Strawberry Hills, NSW). 
Bjornali, E., and L. Støren, 2012, Examining competence factors that encourage innovative behaviour by European higher education graduate professionals, Journal of Small Business and Enterprise Development, 19, 402-423.

Celik, P., M. Storme, A. Davila, and N. Myszkowski, 2016, Work-related curiosity positively predicts worker innovation, Journal of Management Development, 35, 1184-1194.

Cerinsek, G., and S. Dolinsek. 2009, Identifying employees' innovation competency in organizations, International Journal of Innovation and Learning, 6, 164-77.

Committee for Economic Development of Australia, 2015, Australia's future workforce? (CEDA, Melbourne, VIC).

Conway, J., and C. Lance, 2010, What reviewers should expect from authors regarding common method bias in organizational research, Journal of Business and Psychology, 25, $325-334$.

Dale, J. 2015, Preparing business leaders and accountants for future financial leadership, Academic Leadership Series, 6, 88-93.

Davies, A., D. Fidler, and M. Gorbis, 2011, Future work skills 2020, (University of Phoenix Research Institute, Phoenix, AZ).

Deloitte, 2016, Global Human Capital Trends, available at www2.deloitte.com/au/en/pages/human-capital/articles/introduction-humancapital-trends Department of Industry, 2012, Australian Innovation System Report 2012, (Commonwealth of Australia, Canberra, ACT).

Department of Industry, 2014, Engaging Employers in Work Integrated Learning: Current State and Future Priorities (PhillipsKPA, Richmond, VIC).

Dutta, S., B. Lanvin, and S. Wunsch-Vincent, 2016, The global innovation index: Winning with global innovation (World Intellectual Property Organization, Geneva, Switzerland). 
Edwards, D., K. Perkins, J. Pearce, and J. Hong, 2015, Work Integrated Learning in STEM in Australian Universities, (ACER, Melbourne, VIC).

Evans, E., R. Burritt, and J. Guthrie, 2015, Future proofing the profession: Preparing business leaders and finance professionals for 2025 (Chartered Accountants, Sydney, NSW). Foundation for Young Australians, 2016, The new work mindset: 7 new job clusters to help young people to navigate the new work order (FYA, Melbourne, VIC).

Freudenberg, B., M. Brimble, and C. Cameron, 2011, work-integrated learning and generic skill development: The development of business students' generic skills through workintegrated learning, Asia-Pacific Journal of Cooperative Education, 12, 79-93.

Graduate Careers Australia, 2016, Australian Graduate Survey 2015, (Melbourne, GCA). Guilbert, L., J. Bernaud, B. Gouvernet, and J.Rossier, 2016, Employability: review and research prospects, International Journal for Educational and Vocational Guidance, 16, 6989.

Hajkowicz, S., A. Reeson, L. Rudd, A. Bratanova , L. Hodgers, C. Mason, and N. Boughen, 2016, Tomorrow's Digitally Enabled Workforce (CSIRO, Brisbane, QLD).

Hayton, J., and D. Kelley, 2006, A competency-based framework for promoting corporate entrepreneurship, Human Resource Management, 45, 407-27.

Howard, J., 2016, Securing Australia's Future - Capabilities for Australian enterprise innovation (ACOLA, Melbourne, VIC).

Jackling, B., and P. De Lange, 2009, Do accounting graduates' skills meet the expectations of employers? A matter of convergence or divergence, Accounting Education: An International Journal, 18, 369-385.

Jackson, D, 2016a, Re-conceptualising graduate employability: The construction of pre-professional identity in the higher education landscape of practice, Higher Education Research and Development, doi: 10.1080/07294360.2016.1139551. 
Jackson, D, 2016b, Modelling graduate skill transfer from university to the workplace, Journal of Education and Work, 29, 199-231.

Jackson, D., and P. Hancock, 2010, Developing non-technical skills in undergraduate degrees in business and their transfer to the workplace, Education Research and Perspectives, 37, 5284.

Jackson, D., D. Rowbottom, S. Ferns, and D. McLaren, 2016, Employer understanding of Work-Integrated Learning and the challenges of engaging in work-integrated learning opportunities, Studies in Continuing Education, doi: 10.1080/0158037X.2016.1228624. Jackson, P., J. Runde, P. Dobson, and N. Richter, 2015, Identifying mechanisms influencing the emergence and success of innovation within national economies: a realist approach, Policy Sciences, doi: 10.1007/s11077-015-9237-6.

Karmel, T., and D. Carroll, 2016, Has the graduate labour market been swamped? (National Institute of Labour Studies, Flinders University, Adelaide, SA).

Kavanagh, M., and H. Drennan, 2008, What skills and attributes does an accounting graduate need? Evidence from student perceptions and employers, Accounting and Finance, 48, 279 300.

Loughry, M., M. Ohland, and D. Woehr, 2014, Assessing teamwork skills for assurance of learning using CATME team tools, Journal of Marketing Education, 36, 5-19.

Lowden, K., S. Hall, D. Elliot, and J. Lewin, 2011, Employers' perceptions of the employability skills of new graduates, (Edge Foundation, London, UK).

McKinsey, 2014, Compete to Prosper: Improving Australia's Global Competitiveness, (McKinsey Australia, Sydney, NSW).

Michaelis, T., and S. Markham, 2017, Innovation Training: Making Innovation a Core Competency, Research-Technology Management, 60, 36-42. 
Oliver, D., B. Freeman, C. Young, S. Yu, and G. Verma, 2014, Employer satisfaction survey: Report for the Department of Education, (Workplace Research Centre, University of Sydney, Sydney, NSW).

Nair, C., and M. Shah, 2011, Developing an effective student feedback and improvement system: Exemplars with proven success, AUQA Occasional Publications Series 113.

Østergaard, C., B. Timmermans, and K. Kristinsson, 2011, Does a different view create something new? The effect of employee diversity on innovation, Research Policy, 40, 500 509.

Pons, F., J. Ramos, and A. Ramos, 2016, Antecedent variables of innovation behaviors in organizations, European Review of Applied Psychology, 66, 117-126.

Ritter, T., and H. Gemunden, 2003, Network competence: its impact on innovation success and its antecedents, Journal of Business Research, 56, 745-55.

Ritzen, J., 2016, Touchstone on universities and clever Australia, presentation at the Higher Education Conference, March 16, 2016, Canberra.

Rosenberg, C., 2016, Innovation Economy Needs Workers Who Can Shift Fast, available at www.afr.com/opinion/the-innovationeconomy-will-require-accelerated-workplaceskillsshifts-20160308-gnd9py.

Sin, S., A. Reid, and A. Jones, 2012, An Exploration of Students' Conceptions of Accounting Work, Accounting Education, 21, 323-340.

Smith, C., S. Ferns, and L. Russell, 2014, The impact of work integrated learning on student work-readiness - Final Report, (OLT, Canberra, ACT).

Trede, F., R. Macklin, and D. Bridges, 2012, Professional identity development: A review of the Higher Education literature, Studies in Higher Education, 37, 365-384.

UK Commission for Employment and Skills, 2014, The Future of Work: Jobs and Skills in 2030, available at www.gov.uk/government/publications/jobs-and-skills-in-2030. 
Universities Australia, BCA, ACCI, AIG, and ACEN, 2015, National strategy on Work Integrated Learning in university education, available at http://cdn1.acen.edu.au/wpcontent/uploads/2015/03/National-work-integrated learningStrategy-in-university-education032015.pdf

Universities Australia, 2016, Submission to the Inquiry into innovation and creativity: workforce for the new economy, (Universities Australia, Canberra, ACT). University of Melbourne, 2016, Submission to the inquiry into innovation and creativity: Workforce for the new economy (University of Melbourne, Melbourne, VIC).

Utterback, J., 2004, Mastering the Dynamics of Innovation, (Harvard Business School Press, Boston, MA).

Van de Mortel, T., 2008, Faking it: social desirability response bias in self-report research, Australian Journal of Advanced Nursing, 25, 40-48.

Volles, N., 2016, Lifelong learning in the EU: changing conceptualisations, actors, and policies, Studies in Higher Education, 41, 343-363.

Webb, J., and C. Chaffer, 2016, The expectation performance gap in accounting education: a review of generic skills development in UK accounting degrees, Accounting Education, 25, 349-367.

Wojtczuk-Turek, A., and Turek, D., 2015, Innovative behaviour in the workplace: The role of HR flexibility, individual flexibility and psychological capital: the case of Poland, European Journal of Innovation Management, 18, 397-419.

World Bank Group, 2016, World development report 2016: Digital dividends, (World Bank Group, Washington, DC).

World Economic Forum, 2016, The future of jobs: Employment, skills and workforce strategy for the fourth industrial revolution, (World Economic Forum, Geneva, Switzerland). 
Table 1 Background characteristics of 2012-5 Bachelor Accounting and Finance graduates

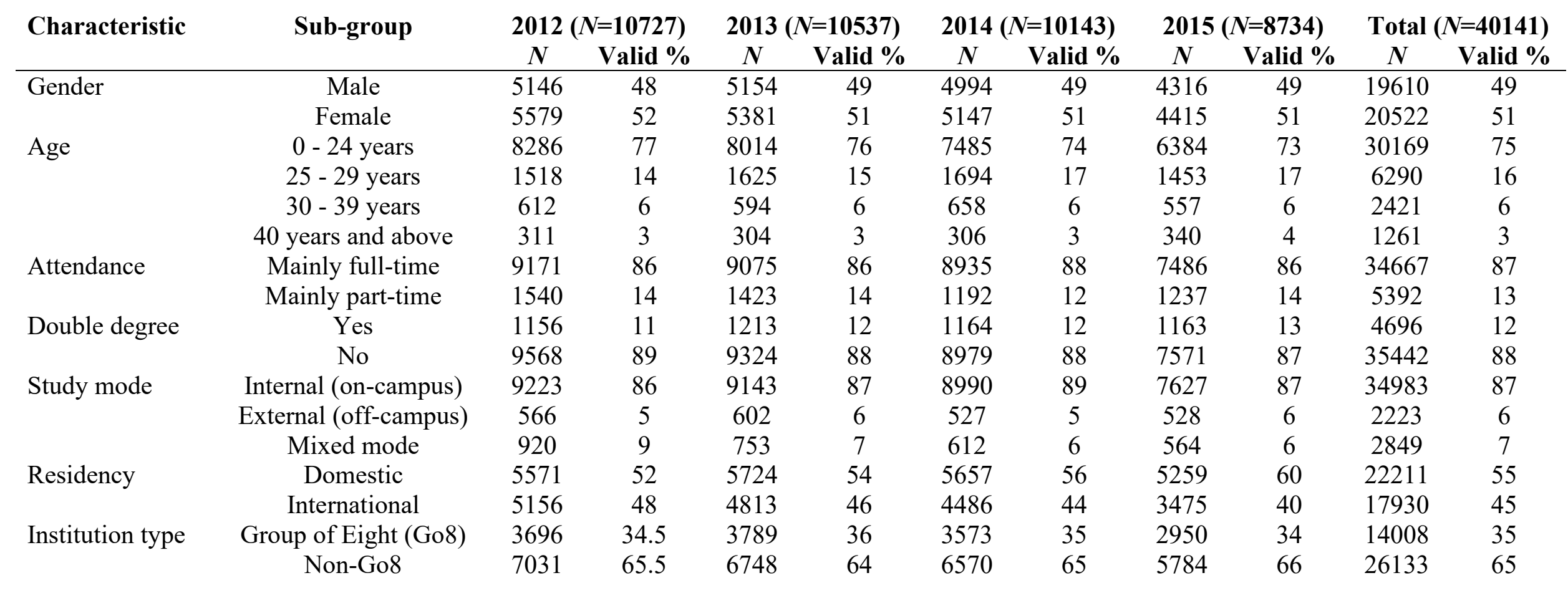


Table 2 Background characteristics of 2013-5 Bachelor Business and Management students

\begin{tabular}{|c|c|c|c|c|c|c|c|c|c|c|c|c|c|c|c|c|c|}
\hline \multirow[t]{3}{*}{ Characteristic } & \multirow[t]{3}{*}{ Sub-group } & \multicolumn{4}{|c|}{$2013(N=17571)$} & \multicolumn{4}{|c|}{$2014(N=16359)$} & \multicolumn{4}{|c|}{$2015(N=23101)$} & \multicolumn{4}{|c|}{ Total $(N=57031)$} \\
\hline & & \multicolumn{2}{|c|}{ Comm } & \multicolumn{2}{|c|}{ Comp } & \multicolumn{2}{|c|}{ Comm } & \multicolumn{2}{|c|}{ Comm } & \multicolumn{2}{|c|}{ Comp } & \multicolumn{2}{|c|}{ Comm } & \multicolumn{2}{|c|}{ Comp } & \multicolumn{2}{|c|}{ Comm } \\
\hline & & $N$ & $\%$ & $N$ & $\%$ & $N$ & $\%$ & $N$ & $\%$ & $N$ & $\%$ & $N$ & $\%$ & $N$ & $\%$ & $N$ & $\%$ \\
\hline \multirow[t]{2}{*}{ Gender } & Male & 5570 & 60.3 & 4976 & 59.7 & 5476 & 60.3 & 4340 & 59.7 & 7495 & 58.4 & 6137 & 59.8 & 18541 & 59.5 & 15453 & 59.7 \\
\hline & Female & 3663 & 39.7 & 3362 & 40.3 & 3608 & 39.7 & 2935 & 40.3 & 5344 & 41.6 & 4125 & 40.2 & 12615 & 40.5 & 10422 & 40.3 \\
\hline \multirow[t]{4}{*}{ Age } & $0-24$ years & 8152 & 88.3 & 7062 & 84.7 & 7957 & 87.6 & 6016 & 82.7 & 11515 & 89.7 & 8533 & 83.2 & 27624 & 88.7 & 21611 & 83.5 \\
\hline & $25-29$ years & 437 & 4.7 & 667 & 8.0 & 422 & 4.6 & 630 & 8.7 & 545 & 4.2 & 913 & 8.9 & 1404 & 4.5 & 2210 & 8.5 \\
\hline & 30 - 39 years & 380 & 4.1 & 387 & 4.6 & 423 & 4.7 & 405 & 5.6 & 466 & 3.6 & 511 & 5.0 & 1269 & 4.1 & 1303 & 5.0 \\
\hline & 40 years plus & 264 & 2.9 & 222 & 2.7 & 282 & 3.1 & 224 & 3.1 & 313 & 2.4 & 305 & 3.0 & 859 & 2.8 & 751 & 2.9 \\
\hline \multirow[t]{2}{*}{ Attendance } & $\begin{array}{l}\text { Mainly full- } \\
\text { time }\end{array}$ & 8474 & 91.8 & 7663 & 91.9 & 8251 & 90.8 & 6619 & 91.0 & 11799 & 91.9 & 9147 & 89.1 & 28524 & 91.6 & 23429 & 90.5 \\
\hline & $\begin{array}{l}\text { Mainly part- } \\
\text { time }\end{array}$ & 759 & 8.2 & 675 & 8.1 & 833 & 9.2 & 656 & 9.0 & 1040 & 8.1 & 1115 & 10.9 & 2632 & 8.4 & 2446 & 9.5 \\
\hline \multirow[t]{2}{*}{ Double degree } & No & 6901 & 74.7 & 7078 & 84.9 & 6643 & 73.1 & 5897 & 81.1 & 9319 & 72.6 & 8589 & 83.7 & 22863 & 73.4 & 21564 & 83.3 \\
\hline & Yes & 2332 & 25.3 & 1260 & 15.1 & 2441 & 26.9 & 1378 & 18.9 & 3520 & 27.4 & 1673 & 16.3 & 8293 & 26.6 & 4311 & 16.7 \\
\hline \multirow[t]{3}{*}{ Study mode } & On-campus & 8525 & 92.3 & 7317 & 87.8 & 8260 & 90.9 & 6188 & 85.1 & 11369 & 88.6 & 8814 & 85.9 & 28154 & 90.4 & 22319 & 86.3 \\
\hline & Off-campus & 450 & 4.9 & 426 & 5.1 & 637 & 7.0 & 521 & 7.2 & 776 & 6.0 & 682 & 6.6 & 1863 & 6.0 & 1629 & 6.3 \\
\hline & Mixed mode & 258 & 2.8 & 595 & 7.1 & 187 & 2.1 & 566 & 7.8 & 694 & 5.4 & 766 & 7.5 & 1139 & 3.7 & 1927 & 7.4 \\
\hline \multirow[t]{2}{*}{ Residency } & Domestic & 7360 & 79.7 & 5385 & 64.6 & 7319 & 80.6 & 5120 & 70.4 & 10433 & 81.3 & 7060 & 68.8 & 25112 & 80.6 & 17565 & 67.9 \\
\hline & International & 1873 & 20.3 & 2953 & 35.4 & 1765 & 19.4 & 2155 & 29.6 & 2406 & 18.7 & 3202 & 31.2 & 6044 & 19.4 & 8310 & 32.1 \\
\hline \multirow[t]{2}{*}{ Institution type } & Non-Go8 & 6212 & 67.3 & 5706 & 68.4 & 6074 & 66.9 & 5005 & 68.8 & 8939 & 69.6 & 6953 & 67.8 & 21225 & 68.1 & 17664 & 68.3 \\
\hline & Go8 & 3021 & 32.7 & 2632 & 31.6 & 3010 & 33.1 & 2270 & 31.2 & 3900 & 30.4 & 3309 & 32.2 & 9931 & 31.9 & 8211 & 31.7 \\
\hline Total & & 9233 & 52.5 & 8338 & 47.5 & 9084 & 55.5 & 7275 & 44.5 & 12839 & 55.6 & 10262 & 44.4 & 31156 & 54.6 & 25875 & 45.4 \\
\hline
\end{tabular}


Table 3 Innovative capabilities among Accounting and Finance graduates

\begin{tabular}{|c|c|c|c|c|c|c|c|c|c|c|c|c|c|c|c|c|}
\hline & & \multicolumn{3}{|c|}{2012} & \multicolumn{3}{|c|}{2013} & \multicolumn{3}{|c|}{2014} & \multicolumn{3}{|c|}{2015} & \multicolumn{3}{|c|}{ Total } \\
\hline & & $\%$ & $M$ & $S D$ & $\%$ & $\boldsymbol{M}$ & $S D$ & $\%$ & M & $S D$ & $\%$ & $M$ & $S D$ & $\%$ & M & $S D$ \\
\hline \multirow{3}{*}{$\begin{array}{l}\text { Ability to work } \\
\text { as a team } \\
\text { member }\end{array}$} & Disagree & 10.6 & 3.74 & .910 & 9.9 & 3.77 & .906 & 10.0 & 3.78 & .916 & 9.5 & 3.82 & .913 & 10.1 & 3.77 & .911 \\
\hline & Neither & 18.7 & & & 18.3 & & & 17.9 & & & 16.6 & & & 17.9 & & \\
\hline & Agree & 70.7 & $N=10418$ & & 71.8 & $N=10262$ & & 72.1 & $N=9696$ & & 73.8 & $N=8370$ & & 72.0 & $N=38746$ & \\
\hline \multirow[t]{3}{*}{ Analytic skills } & Disagree & 5.1 & 3.95 & .784 & 5.0 & 3.97 & .800 & 5.2 & 3.96 & .799 & 5.1 & 3.99 & .801 & 5.1 & 3.97 & .796 \\
\hline & Neither & 13.8 & & & 14.1 & & & 13.8 & & & 12.7 & & & 13.6 & & \\
\hline & Agree & 81.1 & $N=10416$ & & 80.9 & $N=10271$ & & 81.0 & $N=9695$ & & 82.2 & $N=8364$ & & 81.3 & $N=38746$ & \\
\hline \multirow{3}{*}{$\begin{array}{l}\text { Problem-solving } \\
\text { skills }\end{array}$} & Disagree & 5.3 & 3.92 & .773 & 4.8 & 3.95 & .776 & 5.2 & 3.93 & .783 & 4.9 & 3.97 & .787 & 5.1 & 3.94 & .780 \\
\hline & Neither & 14.2 & & & 14.1 & & & 13.8 & & & 13.1 & & & 13.8 & & \\
\hline & Agree & 80.5 & $N=10403$ & & 81.1 & $N=10255$ & & 81.0 & $N=9701$ & & 82.0 & $N=8366$ & & 81.1 & $N=38725$ & \\
\hline \multirow{3}{*}{$\begin{array}{l}\text { Confident about } \\
\text { tackling } \\
\text { unfamiliar } \\
\text { problems }\end{array}$} & Disagree & 6.7 & 3.78 & .815 & 7.0 & 3.80 & .831 & 7.0 & 3.78 & .827 & 6.7 & 3.82 & .837 & 6.9 & 3.79 & .827 \\
\hline & Neither & 21.7 & & & 20.7 & & & 20.5 & & & 19.9 & & & 20.8 & & \\
\hline & Agree & 71.6 & $N=10406$ & & 72.3 & $N=10252$ & & 72.5 & $N=9693$ & & 73.4 & $N=8363$ & & 72.3 & $N=38714$ & \\
\hline \multirow{3}{*}{$\begin{array}{l}\text { Broad overview } \\
\text { of my field of } \\
\text { knowledge }\end{array}$} & Disagree & 5.2 & 3.96 & .780 & 4.8 & 3.97 & .788 & 5.9 & 3.95 & .819 & 5.7 & 3.98 & .817 & 5.4 & 3.96 & .799 \\
\hline & Neither & 12.2 & & & 13.5 & & & 12.0 & & & 11.9 & & & 12.4 & & \\
\hline & Agree & 82.7 & $N=7287$ & & 81.7 & $N=6817$ & & 82.1 & $N=6115$ & & 82.4 & $N=5005$ & & 82.2 & $N=25224$ & \\
\hline \multirow{6}{*}{$\begin{array}{l}\text { Confidence to } \\
\text { investigate new } \\
\text { ideas } \\
\text { Enthusiasm for } \\
\text { learning }\end{array}$} & Disagree & 9.0 & 3.69 & .852 & 8.5 & 3.72 & .856 & 9.0 & 3.70 & .862 & 9.0 & 3.74 & .883 & 8.8 & 3.71 & .862 \\
\hline & Neither & 24.4 & & & 23.8 & & & 23.3 & & & 22.0 & & & 23.5 & & \\
\hline & Agree & 66.6 & $N=7288$ & & 67.7 & $N=6813$ & & 67.8 & $N=6123$ & & 69.0 & $N=4999$ & & 67.7 & $N=25223$ & \\
\hline & Disagree & 11.5 & 3.66 & .935 & 11.0 & 3.67 & .939 & 11.5 & 3.68 & .944 & 11.3 & 3.69 & .942 & 11.3 & 3.67 & .940 \\
\hline & Neither & 22.4 & & & 23.6 & & & 21.7 & & & 22.7 & & & 22.6 & & \\
\hline & Agree & 66.1 & $N=7291$ & & 65.4 & $N=6814$ & & 66.8 & $N=6122$ & & 66.0 & $N=5001$ & & 66.1 & $N=25228$ & \\
\hline \multirow{6}{*}{$\begin{array}{l}\text { Able to apply } \\
\text { principles } \\
\text { learned to new } \\
\text { situations } \\
\text { Value other } \\
\text { perspectives }\end{array}$} & Disagree & 6.0 & 3.85 & .782 & 5.3 & 3.88 & .780 & 6.1 & 3.87 & .803 & 6.2 & 3.89 & .813 & 5.8 & 3.87 & .793 \\
\hline & Neither & 16.3 & & & 16.8 & & & 16.1 & & & 15.1 & & & 16.2 & & \\
\hline & Agree & 77.7 & $N=7287$ & & 77.9 & $N=6802$ & & 77.8 & $N=6118$ & & 78.7 & $N=4997$ & & 78.0 & $N=25204$ & \\
\hline & Disagree & 5.4 & 3.88 & .801 & 5.1 & 3.91 & .799 & 5.5 & 3.90 & .802 & 5.4 & 3.93 & .818 & 5.4 & 3.90 & .804 \\
\hline & Neither & 17.2 & & & 17.0 & & & 15.6 & & & 15.3 & & & 16.3 & & \\
\hline & Agree & 77.4 & $N=7283$ & & 77.9 & $N=6816$ & & 78.9 & $N=6117$ & & 79.3 & $N=4996$ & & 78.3 & $N=25212$ & \\
\hline
\end{tabular}


Table 4 Innovative capabilities among Business and Management students

\begin{tabular}{lcccccc} 
& \multicolumn{3}{c}{ Commencing } & \multicolumn{3}{c}{ Completing } \\
& $\boldsymbol{M}$ & $\boldsymbol{S D}$ & $\boldsymbol{N}$ & $\boldsymbol{M}$ & $\boldsymbol{S D}$ & $\boldsymbol{N}$ \\
\hline Work as a team member & 3.74 & .858 & 3180 & 3.81 & .867 & 3291 \\
Analytic skills & 3.83 & .764 & 3184 & 3.87 & .779 & 3288 \\
Problem-solving skills & 3.83 & .763 & 3187 & 3.86 & .773 & 3294 \\
$\begin{array}{l}\text { Confident about tackling unfamiliar } \\
\text { problems }\end{array}$ & 3.60 & .820 & 3162 & 3.69 & .815 & 3281 \\
Broad overview of my field of & & & & & & \\
knowledge & 3.88 & .757 & 2510 & 3.89 & .791 & 2473 \\
Confidence to investigate new ideas & 3.64 & .831 & 2506 & 3.64 & .873 & 2471 \\
Enthusiasm for learning & 3.64 & .908 & 2483 & 3.49 & .959 & 2463 \\
$\begin{array}{l}\text { Able to apply principles learned to } \\
\text { new situations }\end{array}$ & 3.84 & .784 & 2489 & 3.83 & .783 & 2458 \\
Value other perspectives & 3.83 & .772 & 2491 & 3.83 & .796 & 2466 \\
& & & & & & \\
Critical thinking skills & 3.69 & .851 & 30015 & 3.81 & .869 & 25098 \\
Complex problem solving skills & 3.54 & .869 & 30031 & 3.69 & .874 & 25088 \\
$\quad$ Team work & 3.60 & .956 & 30024 & 3.79 & .948 & 25086 \\
Knowledge of field of study & 3.92 & .820 & 30030 & 3.97 & .829 & 25081
\end{tabular}


Table 5 Variations in graduate innovative capabilities by background characteristics

\begin{tabular}{|c|c|c|c|c|c|c|}
\hline Variable & Category & $d f$ & $M S$ & $\boldsymbol{F}$ & $p$-value & $\eta^{2}$ \\
\hline \multirow[t]{8}{*}{ Age } & Work as a team member & 3 & 18.396 & 22.683 & .000 & .003 \\
\hline & Analytic skills & 3 & 10.454 & 16.541 & .000 & .002 \\
\hline & Problem-solving skills & 3 & 2.344 & 3.900 & .008 & .000 \\
\hline & Confident about tackling unfamiliar problems & 3 & 13.462 & 19.900 & .000 & .002 \\
\hline & Broad overview of my field of knowledge & 3 & 14.144 & 22.246 & .000 & .003 \\
\hline & Confidence to investigate new ideas & 3 & 22.204 & 30.089 & .000 & .004 \\
\hline & Enthusiasm for learning & 3 & 30.992 & 35.210 & .000 & .004 \\
\hline & Apply principles learned to new situations & 3 & 15.683 & 25.047 & .000 & .003 \\
\hline \multirow[t]{5}{*}{ Gender } & Work as a team member & 1 & 43.309 & 53.384 & .000 & .002 \\
\hline & Analytic skills & 1 & 9.158 & 14.477 & .000 & .001 \\
\hline & Confident about tackling unfamiliar problems & 1 & 5.941 & 8.767 & .003 & .000 \\
\hline & Enthusiasm for learning & 1 & 45.467 & 51.563 & .000 & .002 \\
\hline & Value other perspectives & 1 & 26.146 & 40.522 & .000 & .002 \\
\hline \multirow[t]{7}{*}{ Residency } & Work as a team member & 1 & 237.492 & 295.532 & .000 & .012 \\
\hline & Analytic skills & 1 & 19.167 & 30.305 & .000 & .001 \\
\hline & Broad overview of my field of knowledge & 1 & 8.214 & 12.892 & .000 & .001 \\
\hline & Confidence to investigate new ideas & 1 & 65.451 & 88.694 & .000 & .004 \\
\hline & Enthusiasm for learning & 1 & 151.532 & 172.632 & .000 & .007 \\
\hline & Apply principles learned to new situations & 1 & 4.643 & 7.396 & .007 & .000 \\
\hline & Value other perspectives & 1 & 14.411 & 22.315 & .000 & .001 \\
\hline \multirow{7}{*}{$\begin{array}{l}\text { Group-of- } \\
\text { eight }\end{array}$} & Work as a team member & 1 & 19.259 & 23.707 & .000 & .001 \\
\hline & Analytic skills & 1 & 25.224 & 39.897 & .000 & .002 \\
\hline & Problem-solving & 1 & 19.190 & 31.966 & .000 & .001 \\
\hline & Broad overview of my field of knowledge & 1 & 26.008 & 40.867 & .000 & .002 \\
\hline & Confidence to investigate new ideas & 1 & 11.077 & 14.966 & .000 & .001 \\
\hline & Enthusiasm for learning & 1 & 16.452 & 18.627 & .000 & .001 \\
\hline & Value other perspectives & 1 & 18.799 & 29.118 & .000 & .001 \\
\hline
\end{tabular}


Table 6 Variations in student innovative capabilities by background characteristics

\begin{tabular}{|c|c|c|c|c|c|c|}
\hline Variable & Category & $d f$ & $M S$ & $\boldsymbol{F}$ & $p$-value & $\eta^{2}$ \\
\hline \multirow[t]{5}{*}{ Age } & Work as a team member & 3 & 4.482 & 6.005 & .000 & .007 \\
\hline & Confident about tackling unfamiliar problems & 3 & 3.538 & 5.323 & .001 & .007 \\
\hline & Broad overview of my field of knowledge & 3 & 3.059 & 4.982 & .002 & .006 \\
\hline & Enthusiasm for learning & 3 & 5.278 & 5.802 & .001 & .007 \\
\hline & Apply principles learned to new situations & 3 & 2.941 & 4.828 & .002 & .006 \\
\hline \multirow[t]{2}{*}{ Gender } & Value other perspectives & 1 & 9.384 & 14.947 & .000 & .006 \\
\hline & Complex problem-solving & 1 & 7.433 & 9.589 & .002 & .004 \\
\hline \multirow[t]{2}{*}{ Residency } & Value other perspectives & 1 & 5.403 & 8.584 & .003 & .004 \\
\hline & Knowledge of field of study & 1 & 8.836 & 13.541 & .000 & .006 \\
\hline \multirow{5}{*}{$\begin{array}{l}\text { Group-of- } \\
\text { eight }\end{array}$} & Confident about tackling unfamiliar problems & 1 & 7.964 & 11.970 & .001 & .005 \\
\hline & Confidence to investigate new ideas & 1 & 8.040 & 10.706 & .001 & .004 \\
\hline & Enthusiasm for learning & 1 & 7.899 & 8.659 & .003 & .004 \\
\hline & Complex problem-solving & 1 & 9.422 & 12.167 & .000 & .005 \\
\hline & Teamwork & 1 & 8.488 & 9.299 & .002 & .004 \\
\hline
\end{tabular}

